\title{
Epidemiology of Admissions in a Pediatric Emergency Department in Albert Royer Hospital Dakar
}

\author{
Aliou Thiongane ${ }^{1}$, Aliou Abdoulaye Ndongo², Amadou Sow ${ }^{3}$, Younoussa Keita², Djibril Boiro ${ }^{3}$, \\ Yaye Joor Dieng', Idrissa Basse ${ }^{4}$, Ndiogou Seck ${ }^{5}$, Lisimo Abwa Hilaire ${ }^{1}$, Papa Moctar Faye ${ }^{1}$, \\ Amadou Lamine Fall'1, Assane Sylla², Saliou Diouf', Ousmane Ndiaye ${ }^{1}$ \\ ${ }^{1}$ Centre Hospitalier National d'Enfants Albert Royer, Dakar, Sénégal \\ ${ }^{2}$ Service de pédiatrie Hôpital Le Dantec, Dakar, Sénégal \\ ${ }^{3}$ Service de pédiatrie Hôpital Abass ndao, Dakar, Sénégal \\ ${ }^{4}$ Centre Hospitalier National d'Enfants de Diamniadio, Dakar, Sénégal \\ ${ }^{5}$ Service de pédiatrie Hôpital régional, Saint Louis, Sénégal \\ ${ }^{6}$ Service de pédiatrie Hôpital Dalal Jamm, Dakar, Sénégal \\ Email: *aliou.thiongane@ucad.edu.sn
}

How to cite this paper: Thiongane, A., Ndongo, A.A., Sow, A., Keita, Y., Boiro, D., Dieng, Y.J., Basse, I., Seck, N., Hilaire, L.A., Faye, P.M., Fall, A.L., Sylla, A., Diouf, S. and Ndiaye, O. (2022) Epidemiology of Admissions in a Pediatric Emergency Department in Albert Royer Hospital Dakar. Open Journal of Pediatrics, 12, 188-195.

https://doi.org/10.4236/ojped.2022.121020

Received: January 17, 2022

Accepted: March 5, 2022

Published: March 8, 2022

Copyright $\odot 2022$ by author(s) and Scientific Research Publishing Inc. This work is licensed under the Creative Commons Attribution International License (CC BY 4.0).

http://creativecommons.org/licenses/by/4.0/ (c) (i) Open Access

\begin{abstract}
Background: Pediatric emergencies are a public health priority in Senegal. The objective was to describe the epidemiology of admissions to the emergency department of the Albert Royer National Children's Hospital in Dakar, Senegal. Methods: Prospective, descriptive and analytical study over a period of 4 months (January-April 2020). The study population was children admitted for vital distress. Results: A total of 300 children met the inclusion criteria and represented the study population (2.83\%). The majority (70.67\%) were younger than 60 months, compared with $2.00 \%$ of newborns. Boys represented $53.8 \%$, sex ratio 1.16 . A proportion of $35.1 \%$ was referred. More than half of our patients $(55.88 \%)$ were managed within 30 minutes of arrival. Medicalized transport concerned $21.5 \%$ against $78.5 \%$ of nonmedicalized. Emergencies were dominated by respiratory distress (56.33\%), dehydration (29\%) and shock (13.33\%). We recorded 16 deaths $(5.3 \%)$. This mortality was significantly related to the low socio-economic level $(\mathrm{p}=0.000)$, as well as the young age of the children $(\mathrm{p}=0.01)$. Conclusion: Life-threatening emergencies are frequent and responsible for significant lethality. Health policy efforts are still needed to reduce this infant and child morbidity and mortality.
\end{abstract}

\section{Keywords}

Children, Emergencies, Morbidity, Mortality 


\section{Introduction}

Pediatric emergencies represent clinical situations with life-threatening risks in the absence of rapid and adequate management. They are a public health priority in the world and in Africa in particular because of their considerable morbidity and mortality. Pediatric emergencies are nowadays one of the most sensitive areas of medicine and are the subject of questioning in many countries, both in the North and in the South [1]. Every year, millions of children die, most often from preventable or treatable diseases. Emergency department-related morbidity and mortality is a major scourge in low- and middle-income countries. To address this situation, the world has made significant progress in reducing child mortality in recent years. Globally, the under-five mortality rate has fallen from 93 deaths per 1000 live births in 1990 to 41 in 2016 and 38 in 2019. This is equivalent to 01 in 11 children dying before reaching the age of 05 in 1990 compared to 01 in 27 children in 2019 [2]. This remarkable progress in improving child survival since 2000 has saved the lives of 50 million children under the age of five worldwide. Sub-Saharan Africa remains the region with the highest under-five mortality rate in the world, with 1 in 13 children dying before their fifth birthday, 20 years lower than the global average of 1 in 13 in 1999 [2]. Globally, the risk of infant and child mortality, i.e., the risk of death before the age of five, is $37 \%$ according to the DHS 2020 [3]. The reduction of the mortality rate requires construction of infrastructure, acquisition of the necessary materials for the adequate management of emergencies and continuous training of personnel [4]. Since the 1990s, the increasing use of pediatric emergency departments worldwide has highlighted the need for prioritization of care.

Thus the implementation of efficient sorting tools has become essential in emergency departments in order to improve waiting times, flow management and patient safety. Children under 60 months of age are the most vulnerable target. Pediatric emergencies are dominated by infectious diseases (neonatal infections, sepsis, malaria and meningitis), respiratory diseases (pneumonia, bronchiolitis, asthma), metabolic diseases (acute dehydration, diabetic ketoacidosis), neonatal emergencies (perinatal asphyxia, respiratory distress in newborns). A good control and an adequate management of its various pathologies will make it possible to reduce this morbi-mortality related to the urgencies [5]. The objective was to describe the epidemiology of admissions to the emergency department of the Albert Royer National Children's Hospital in Dakar, Senegal to improve the management of life-threatening emergencies and reduce morbidity and mortality.

\section{Methods}

\subsection{The Site of the Study}

The study took place in the emergency department of the Albert Royer National Children's Hospital in Dakar. All children aged 0 - 15 years are admitted to this department for consultation for any reason. It includes a triage unit, an emer- 
gency room where vital emergencies are treated, a short-term hospitalization room and ambulatory follow-up boxes.

\subsection{Type and Duration of the Study}

Prospective, descriptive and analytical study over a period of 4 months (JanuaryApril 2020).

\subsection{Study Population}

\subsubsection{Inclusion Criteria}

Children admitted in vital distress aged 0 to 15 years hospitalized in the department during the study period. Any child with a severe clinical situation with a risk of death was considered to be in vital distress.

\subsubsection{Non-Inclusion Criteria}

- Deaths on arrival.

- No life-threatening condition on admission.

- No parental consent.

\subsection{Data Collection and Analysis}

The following data were collected on the basis of a pre-established questionnaire:

- Sociodemographic: age, gender, socioeconomic level.

- Clinical: type of transport, reasons for consultation, diagnosis on admission, monitoring of vital signs, emergency procedures performed.

- Evolution: resolution, death.

The data were entered into SPHINX v5. Statistical analysis was done with SPSS (Statistical Package For Social Sciences) Version 18, and tables and graphs with Excel. Quantitative variables were expressed as mean and standard deviation; qualitative variables as percentage.

\section{Results}

A total of 300 children met the inclusion criteria and represented the study population. The majority of our patients (70.67\%) were younger than 60 months, compared with $2.00 \%$ of newborns (Table 1 ). There was a male predominance (53.8\%). The sex ratio was 1.16 . The largest number of our patients $(40.3 \%)$ came from the suburbs, followed by the city of Dakar (39.4\%), Regions (19.9\%) and $(0.5 \%)$ from neighboring countries. Nearly half of patients $(49.3 \%)$ came from families of average socioeconomic level. The majority of our patients (64.9\%) were self-referred versus $35.1 \%$ of referral. A proportion of $39.24 \%$ were referred for worsening of their clinical condition, $31.65 \%$ for exploration and $13.5 \%$ for unavailability of bed. More than half (57.4\%) of our referred patients had received care before being referred, while $42.6 \%$ of referrals had not received anything before being referred. The average time taken by our patients before the consultation was 2.7 days ( $1-7$ days). More than half of patients (55.88\%) were attended to within 30 minutes of arrival. Medical referrals by ambulance 
concerned $21.5 \%$ against $78.5 \%$ of non-medical transport. A total of $40.51 \%$ were referred by pediatric services, $32 \%$ by a health center, $10 \%$ by private structures, $8.9 \%$ by health posts and $5.10 \%$ by pediatric surgery. The reasons for referral were vital risk (39.24\%), diagnostic difficulties (31.65\%), lack of available beds (13.5\%) and $10.80 \%$ because of urgency felt by the parents. The consultation time was 3 days in $42.65 \%$ of patients with an average of 2.7 days ( 1 - 7 days). Monitoring of vital signs included temperature and heart rate $(86.33 \%)$, respiratory rate $(82 \%)$, oxygen saturation (82\%), blood pressure (34\%) (Table 2). Emergencies were dominated by respiratory distress (56.33\%), dehydration (29\%) and shock (13.33\%) (Table 3 ). Respiratory pathologies accounted for $26 \%$, neurological pathologies for $15.11 \%$, haemato-oncological pathologies for $14.67 \%$, cardiac pathologies for $14.22 \%$, digestive pathologies for $12 \%$ and infectious pathologies for $7.11 \%$ (Figure 1). Therapeutically, the emergency procedures were peripheral vascular access (98\%), intraosseous access $(2.00 \%)$, oxygen therapy (68.33\%), vascular filling (13.66\%) and cardiopulmonary resuscitation (5\%) (Table $3)$. The outcome was favorable with recovery for the majority of patients $(94.7 \%)$. We recorded 16 deaths (5.3\%). The majority of deaths (66.67\%) occurred between 24 and 48 hours. The largest number of our patients $(33.30 \%)$ died of cardiac causes and $30.60 \%$ of severe sepsis (Figure 2). The determinants of mortality were young age less than 60 months $(91.70 \%)(\mathrm{p}=0.01)$, male gender $(83.3 \%)(\mathrm{p}=$ 0.03 ), low socioeconomic level ( $p<0.000)$, origin of residence $(\mathrm{p}=0.02)$, nonmedical transport ( $\mathrm{p}=0.22$, non-significant relationship), non-availability of emergency medication on patient admission ( $\mathrm{p}=0.06$, non-significant relationship),

Table 1. Distribution of children by age group.

\begin{tabular}{ccc}
\hline Age group & Number & Percentage \% \\
\hline $0-28$ days & 6 & 2.00 \\
$1-59$ months & 212 & 70.67 \\
$60-191$ months & 82 & 27.33 \\
Total & 300 & 100.0 \\
\hline
\end{tabular}

Table 2. Monitoring of vital signs.

\begin{tabular}{ccc}
\hline Settings & Number & Percentage \% \\
\hline Temperature & 259 & 86.33 \\
Rate cardiac & 259 & 86.33 \\
Rate respiratory & 246 & 82.00 \\
SpO2 & 246 & 82.00 \\
Glasgow scale & 200 & 66.66 \\
Capilary glucose & 123 & 41.00 \\
Skin recoloration time & 123 & 41.00 \\
Blood pressure & 102 & 34.00
\end{tabular}


Table 3. Medical emergencies and procedures.

\begin{tabular}{llcc}
\hline Settings & & Number & Percentage \% \\
\hline & Respiratory distress & 169 & 56.33 \\
& Dehydration & 87 & 29.00 \\
& Shock & 40 & 13.33 \\
Medical Emergencies & Status epilepticus & 24 & 8.00 \\
& Comas & 21 & 7.00 \\
& cardio-respiratory arrest & 8 & 2.66 \\
& Miscellaneous & 18 & 6.00 \\
\hline \multirow{2}{*}{$\begin{array}{l}\text { Emergency procedures } \\
\text { performed on admission }\end{array}$} & Peripheral vascular accesses & 294 & 98.00 \\
& Volume expansion & 250 & 83.33 \\
& Cardio-pulmonary resuscitation & 15 & 68.33 \\
& Oxygenotherapy & 205 & 13.66 \\
& Intraosseous access & 41 & 2.00 \\
& Miscellaneous & 30 & 10.00 \\
\hline & & &
\end{tabular}

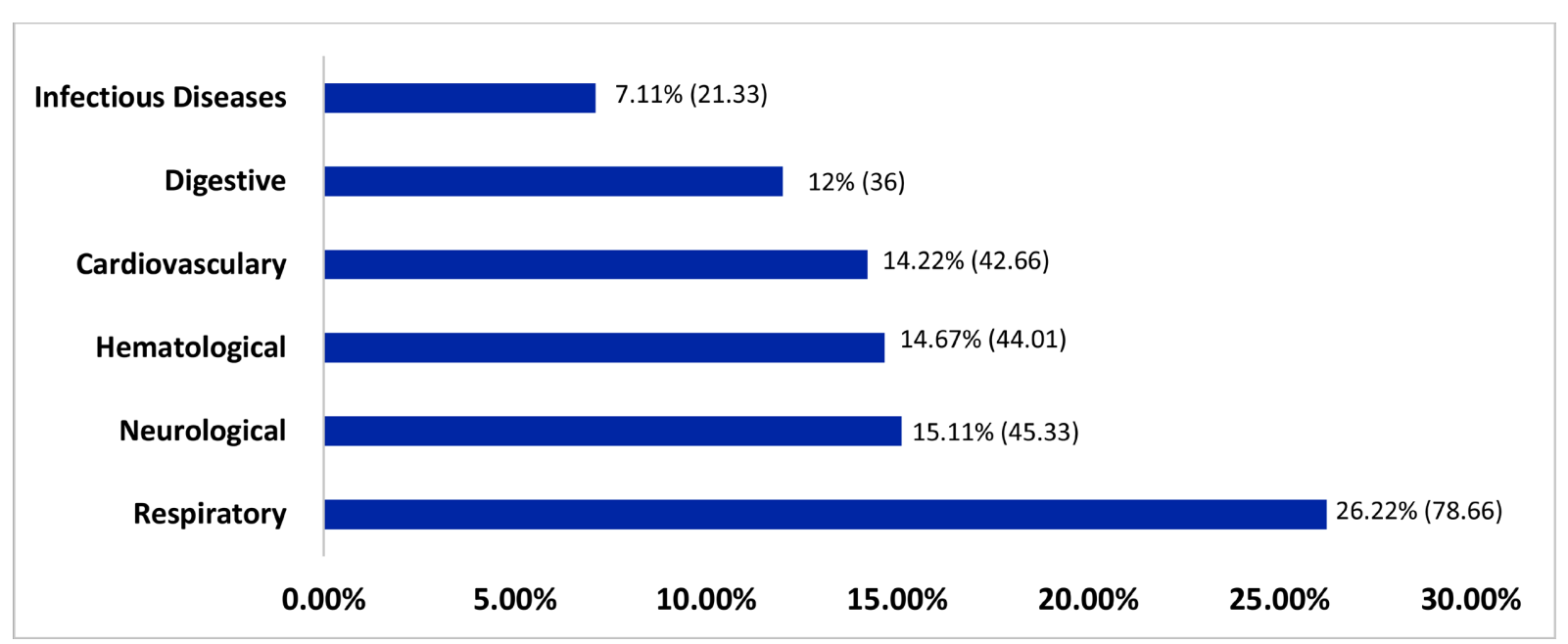

Figure 1. Distribution of patients according to the pathologies of admissions.
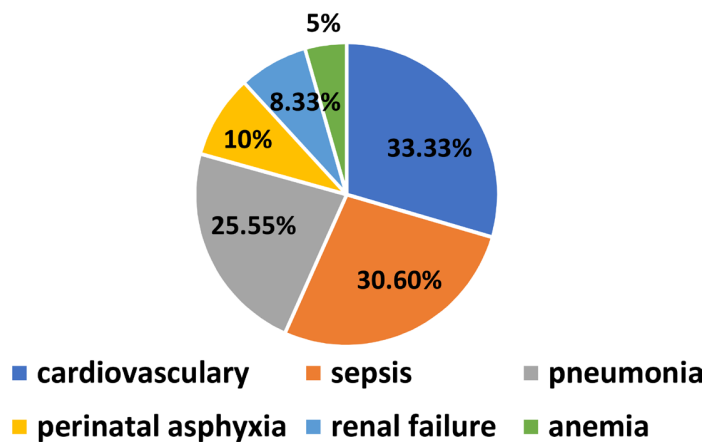

Figure 2. Distribution of children by leading causes of death. 
cardiac pathologies $(\mathrm{p}=0.03$, severe sepsis $(\mathrm{p}=0.02)$.

\section{Comments}

Of the 10.600 children admitted for consultation in the department, 300 were admitted for a life-threatening emergency, i.e., an emergency morbidity rate of $2.83 \%$. This rate seems to be high, but is nevertheless justified by the often late consultation time that can lead to complications. In Switzerland a lower rate was noted $(0.46 \%)$ [6]. Elsewhere in Thailand a similar rate has been noted $(2.46 \%)$ [7]. Pediatric life-threatening emergencies varied globally between $1 \%$ and $5 \%$ according to the literature [8]. The average age of the children was 47 months. Children under 5 years of age were the most vulnerable (70.67\%). Child mortality is a public health priority in low-income countries. There are several strategies put in place by WHO and the countries concerned to reduce this scourge. Data from the literature confirm this predominance of under 5 years of age [9-11]. The natural vulnerability of boys was noted in the study with a male predominance (53.8\%). Late recourse to care is often noted in emergency services. This explains the severity of the clinical pictures and the frequency of complications. Nearly half of the patients had consulted after 3 days of evolution (42.65\%). In Africa in general, delay in seeking hospital care is often reported. The remoteness and/or isolation of certain geographical areas that are difficult to access, transportation difficulties, certain beliefs and the use of traditional practitioners first, partly justify the delay in consultation compared to developed countries. Patient transport was not medicalized in the vast majority of cases $(78.5 \%)$. This is a significant factor in mortality. However, a large proportion of the patients came directly from home, which explains the predominance of nonmedicalized transport. Similar data are noted in Africa [12] [13]. Optimal management of emergencies also involves a good medical transport system with well equipped ambulances and well trained personnel. Emergency measures should be initiated as soon as the clinical situation is diagnosed and recognized. Any delay in management increases the risk of death. Vital sign monitoring is an essential step in effective emergency management. It requires adequate equipment and experienced personnel. Due to a lack of technical means it was not effective in all patients. In addition, vital signs were monitored in the majority of patients for temperature, heart rate, respiratory rate and pulse oxygen saturation $(86.33 \%$, $86.33 \%, 82 \%$ and $82 \%$ respectively). Blood pressure, on the other hand, was monitored in a small proportion of patients (34\%), probably due to a lack of adequate equipment. The five main pathologies noted were respiratory (26\%), neurological (15.11\%), cardiac (14.22\%), digestive (12\%) and infectious (7.11\%). The morbidity of emergencies in children is dominated by respiratory problems, particularly infectious ones such as pneumonia which, according to the WHO, is the second leading cause of infant and child mortality [9]. The mortality rate was estimated to be $5.30 \%$ lower than in previous studies conducted in Africa in emergency departments [14]. The improvement of the reception and manage- 
ment of children in vital distress has reduced this mortality in the unit. A higher mortality rate was noted in Switzerland (7.2\%) [6], lower in France (0.1\%) [15]. This mortality was significantly related to the low socio-economic level $(\mathrm{p}=$ $0.000)$, as well as to the young age of the children $(\mathrm{p}=0.01)$. Mortality in pediatric emergencies is due to several factors that are often interrelated the economic precariousness of populations, late recourse to care and inadequate management in pre-hospital medical centers. Controlling these factors is a major asset for achieving the sustainable development objectives (SDO). However, this study has some limitations, notably the short duration of the study (4 months), which does not allow the evaluation of seasonal variations, but also the inadequacy of the technical platform, which meant that not all vital signs were monitored in all patients.

\section{Conclusion}

Pediatric emergencies are frequent and responsible for significant lethality. Children under 5 years of age are more vulnerable. Health policy efforts are still needed to reduce this infant and child morbidity and mortality.

\section{Conflicts of Interest}

The authors declare no conflicts of interest regarding the publication of this paper.

\section{References}

[1] Dan, V., Hazoume, F.A., Ayivi, B. and Koumakpai, S. (1991) Prise en charge des urgences du nourrisson et de l'enfant: Aspects actuels et perceptive d'avenir. Service de pédiatrie et génétique médicale du Centre National Hospitalier et Universitaire de Cotonou (Benin). Médecine d Afrique Noire, 38, 752-759.

[2] Organisation Mondiale De La Santé (2020) Enfants: améliorer leur survie et leur bien-être. Principaux faits, septembre 2020.

[3] Sénégal: Enquête Démographique et de Santé Continue (EDS-Continue) (2019) Rapport sur les Indicateurs Clés, p 15.

[4] Organisation Mondiale De La Sante (2010) Triage, évaluation et traitement d'urgence (TETU) guide de participant.

[5] OMD (2016) Programme Des Nations Unies Pour Le Developpement Des OMD au développement durable pour tous (ODD): Ce que nous avons retenu de 15 années de pratique.

[6] Lutz, N., Vandermensbrugghe, N.G., Dolci, M., et al. (2014) Pediatric Emergencies Admitted in the Resuscitation Room of a Swiss University Hospital. Pediatric Emergency Care, 30, 699-704. https://doi.org/10.1097/PEC.0000000000000231

[7] Phattharapornjaroen, P., Sittichanbuncha, Y., Atiksawedparit, P. and Sawanyawisuth, K. (2021) Characteristics of Pediatric Emergency and Risk Factors for Life-Saving Interventions. Global Pediatric Health, 8, 1-4. https://doi.org/10.1177/2333794X21990340

[8] Owens, P.L., Barrett, M.L., Gibson, T.B., et al. (2010) Emergency Department Care in the United States: A Profile of National Data Sources. Annals of Emergency Medicine, 56, 150-165. https://doi.org/10.1016/j.annemergmed.2009.11.022 
[9] Azoumah, D.K., et al. (2010) Les urgences médicales pédiatriques au CHU-Campus de Lomé Aspect épidémiologique. Journal de la Recherche Scientifique de 1 Université de Lomé, 12, 1-4. https://doi.org/10.4314/jrsul.v12i2.68040

[10] Dembélé, A., Cissé, M.E., Diakité, A.A., Maïga, B., Doumbia, A.K., Diakité, F.L. and Koné, Y. (2020) Étude épidémio-clinique des références aux urgences pédiatriques du CHU Gabriel Touré. Mali Santé Publique, 10, 29-33.

[11] Sylla, A., Guèye, M., Diouf, S., Ndiaye, O., Fall, A., Faye, B., Moreira, C., Sall, M.G. and Sow, H. (2009) Les urgences pédiatriques à Dakar, Sénégal. Facteurs de risque de décès. Médecine d Afrique Noire, 31, 495-500.

[12] Atanda, H.L., Porte, J., Force-Barge, P. and Rodier, J. (1994) Place des urgences médicales pédiatriques dans un service médical à Pointe-Noire. Médecine d Afrique Noire, 41, 17-20.

[13] Fla, K., Diarra, Y., Lassina, D., Désiré, N. and Alphonse, S. (2007) Morbidité et mortalité néonatale de 2002 à 2006 au Centre Hospitalier Universitaire pédiatrique Charles de Gaulle de Ouagadougou (Burkina Faso). Cahiers Santé, 17, 187-191.

[14] Fall, A.L., Ndiaye, O., Diouf, S., Camara, B., Sylla, A., Diouf, E., Ba, M., Sow, H.D. and Kuakuvi, N. (2007) Prise en charge de transfert des urgences pédiatriques: contraintes, cout et pronostic. Etude prospective à l'hôpital d'enfants Albert Royer du centre Hospitalier Universitaire de Dakar. Médecine d’ Afrique Noire, $N^{\circ} 5410,533-$ 537.

[15] Claudet, I., Bounes, V., Frédérici, S., et al. (2009) Epidemiology of Admissions in a Pediatric Resuscitation Room. Pediatric Emergency Care, 25, 312-316. https://doi.org/10.1097/PEC.0b013e3181a341ac 